MARQUES, P.A.A.; BALDOTTO, P.V.; SANTOS, A.C.P.; OLIVEIRA, L. Qualidade de mudas de alface formadas em bandejas de isopor com diferentes números de células. Horticultura Brasileira, Brasília, v. 21, n. 4, p. 649-651, outubro-dezembro 2003.

\title{
Qualidade de mudas de alface formadas em bandejas de isopor com diferentes números de células
}

\author{
Patrícia Angélica A. Marques ${ }^{1}$; Pedro Veridiano Baldotto ${ }^{2}$; Ana Cláudia P. Santos ${ }^{2}$; Leandro de Oliveira ${ }^{2}$ \\ ${ }^{1}$ Doutoranda, ESALQ, Av. Pádua Dias, 11, C. Postal 09, 13418-900 Piracicaba-SP; E-mail: paamarqu@esalq.usp.br. ${ }^{2}$ UNOESTE, \\ Faculdade de Agronomia, Rod. Raposo Tavares, Km 572, Bairro Limoeiro, 19067-175, Presidente Prudente-SP; E-mail: \\ anaclau@agro.unoeste.br.
}

\begin{abstract}
RESUMO
Avaliaram-se os efeitos de três tipos de bandejas de isopor sobre a produção de mudas de alface cultivar Vera, e o posterior desempenho das plantas no campo. Para os experimentos de avaliação de mudas e de plantas adultas, os delineamentos foram o de blocos e inteiramente casualizado, respectivamente. Aos 26 dias após a semeadura foram avaliados o comprimento de raiz e o número de folhas das mudas. Após o transplante para os canteiros, mediram-se o comprimento da raiz e pesos da matéria fresca e seca da parte aérea. As melhores mudas foram produzidas na bandeja com células de maior volume T1 (128 células). Na planta adulta observou-se que as mudas do tratamento T1 (128 células) e T2 (200 células) não apresentaram diferenças significativas quanto ao desempenho de campo. O tratamento T3 (288 células), com menor volume de substrato, produziu as piores mudas e apresentou o pior desempenho da produção de campo.
\end{abstract}

Palavras-chave: Lactuca sativa L., volume de substrato, produção vegetal.

\begin{abstract}
Lettuce seedling quality using polystirene trays with different cell numbers

Lettuce cultivar Vera seedling production and performance in the field were tested using three different types of polystirene trays. The experiment for seedling production was set on randomized complete block design. For field evaluations the experimental design was completely randomized. At 26 days after sowing date, root size and leaf number per plant were evaluated. After transplanting to the field, production was evaluated by the root size and shoot fresh and dry weights. The best seedlings were obtained in the tray with greater cell volume (T1=128 cells). Seedlings from T1 (128 cells) and T2 ( 200 cells) presented similar performance in the field. T3 (288 cells), with a smaller volume of substrate, produced the worst seedlings and lowest yield.
\end{abstract}

Keywords: Lactuca sativa L., substrate volume, crop production.

(Recebido para publicação em 12 de outubro de 2002 e aceito em 10 de outubro de 2003)

A alface (Lactuca sativa L.) é uma das hortaliças folhosas mais consumidas no Brasil. Em virtude de sua alta perecibilidade e baixa resistência ao transporte, é cultivada próxima aos grandes centros consumidores, nos chamados cinturões verdes (Nicoulaud et al., 1990; Silva et al., 2000b). No Brasil a maior produção de alface concentra-se no Estado de São Paulo, onde são exploradas cultivares de verão e inverno em diferentes épocas sob condições de irrigação (Andrade Júnior et al., 1992).

A produção de mudas de hortaliças constitui-se numa das etapas mais importantes do sistema produtivo (Minami, 1995; Silva Júnior et al., 1995). Dela depende o desempenho final das plantas nos canteiros de produção, tanto do ponto de vista nutricional, quanto do tempo necessário para a colheita e, consequentemente, do número de ciclos possíveis por ano (Carmello, 1995).

A produção de mudas, em canteiros e campo aberto, é um sistema pouco efi- ciente quanto ao aspecto fitossanitário. As sementes ficam em condições desuniformes (solo, chuvas, temperaturas extremas), e conseqüentemente, a germinação, emergência e crescimento das plântulas também são irregulares, levando à obtenção de estandes falhos e desuniformes (Minami, 1995).

A semeadura indireta para a produção de mudas e posterior transplante para a lavoura definitiva é o método de propagação mais empregado para a maioria das espécies de hortaliças (Filgueira, 2000). A modernização deste sistema somente teve início em 1985, com a adoção do sistema de bandejas multicelulares, permitindo a obtenção de plantas mais vigorosas e produtivas.

O sistema de bandejas proporciona maior cuidado na fase de germinação e emergência, fazendo com que, muitas vezes, uma semente origine uma planta, além de proporcionar menor custo no controle de pragas e doenças e alto índice de pegamento após o transplante
(Minami, 1995; Modolo \& Tessarioli Neto, 1999). Oliveira et al. (1993) citam também como vantagens desse método a economia de substrato e da melhor utilização da área de viveiro.

O problema agronômico original de produção de mudas em recipientes é o de assegurar o crescimento e produção de biomassa aérea com volume limitado de solo (Sancho, 1988). Assim, quanto menor for o espaço disponível às raízes, mais difícil será o suprimento de fatores de produção que garantam o crescimento otimizado e desenvolvimento normal da muda (Menezes Júnior et al., 2000). O tamanho do recipiente e o tipo do substrato são os primeiros aspectos a serem investigados para que seja garantida a produção de mudas de boa qualidade. $\mathrm{O}$ primeiro afeta diretamente o volume disponível para o desenvolvimento das raízes e o segundo, exerce uma influência marcante na arquitetura do sistema radicular e no estado nutricional das plantas, afetando 
Tabela 1. Médias obtidas para comprimento de raiz $(\mathrm{cm})$ e médias de número de folhas das mudas de alface produzidas nos diferentes tipos de bandeja, 28 dias após a semeadura. Presidente Prudente, UNOESTE, 2001.

\begin{tabular}{lcc}
\hline Tratamentos & $\begin{array}{c}\text { Médias do } \\
\text { comprimento de raiz } \\
(\mathbf{c m})\end{array}$ & $\begin{array}{c}\text { Médias do número de } \\
\text { folhas }\end{array}$ \\
\hline T1 -128 células & $8,10 \mathrm{a}$ & $5,45 \mathrm{a}$ \\
$\mathrm{T} 2-200$ células & $6,30 \mathrm{~b}$ & $5,00 \mathrm{~b}$ \\
$\mathrm{~T} 3-288$ células & $5,00 \mathrm{c}$ & $4,55 \mathrm{c}$ \\
\hline $\mathrm{CV}(\%)$ & 16,2 & 8,34 \\
\hline
\end{tabular}

*Médias seguidas por letras distintas na coluna, diferem entre si pelo teste de Tukey a $5 \%$.

profundamente a qualidade das mudas (Carneiro,1983; Latimer, 1991).

No mercado há diversos modelos de bandejas com diferentes números de células individuais; profundidades e volumes diversos; também com formatos variáveis, podendo ser redondas, piramidais, cilíndricas e com possibilidade de reutilização (Modolo \& Tessarioli Neto, 1999).

Sistemas de produção de mudas de alface envolvem a utilização de bandejas de isopor com número variável de células $(72 ; 128 ; 200$ e 288$)$ para a avaliação de diversos fatores tais como fertilização (Dematte et al., 1995; Souza et al., 2002), tipos de substratos (Godoy et al., 1995; Menezes Junior \& Fernandes, 1999; Menezes Junior et al., 2000) e lâminas de irrigação associadas a condicionadores de solo (Verdial et al., 1996; Luz et al., 2000; Roda Junior et al., 2002).

Para avaliar o efeito de diferentes tipos de bandejas sobre a produção de mudas de alface cv. Regina, Silva et al. (2000a) testaram bandejas de 128 e 72 células. O menor tempo para o transplante e a maior área foliar foram obtidos na bandeja de 72 células, sendo ainda que todos os compostos testados produziram mudas de melhor qualidade neste tipo de bandeja.

O objetivo deste trabalho foi o de avaliar o desenvolvimento de mudas de alface cv. Vera produzidas no sistema de bandejas de isopor utilizando três tipos de bandejas diferentes em relação ao número, volume e altura das células. Avaliou-se também a produção a campo destas mudas para visualizar o efeito das bandejas na planta adulta.

\section{MATERIAL E MÉTODOS}

O trabalho foi conduzido em campo na Universidade do Oeste Paulista em Presidente Prudente. Para a produção de mudas utilizou-se o sistema de bandejas de isopor, sendo avaliados três tipos de bandejas: $\mathrm{T} 1=128$ células, 25,09 $\mathrm{cm}^{3}, 3,7 \times 5,5 \mathrm{~cm} ; \mathrm{T} 2=200$ células, 12,39 $\mathrm{cm}^{3}, 2,6 \times 5,5 \mathrm{~cm} ; \mathrm{T} 3=288$ células, 7,93 $\mathrm{cm}^{3}, 2,3 \times 4,5 \mathrm{~cm}$.

O substrato das bandejas foi composto com material orgânico (esterco de bovino), vermiculita expandida e casca de pinus. Para a condução a campo as mudas foram transferidas para canteiros preparados com $3 \mathrm{~kg} . \mathrm{m}^{-2}$ de esterco de galinha e $200 \mathrm{~g}$. $\mathrm{m}^{-2}$ de adubo 4-14-8. A adubação de cobertura foi realizada com 15 g. $\mathrm{m}^{-2}$ de uréia em duas aplicações.

O delineamento estatístico para a avaliação das mudas foi o de blocos ao acaso, com 20 repetições. Foram estudados três tipos de bandejas (tratamentos), sendo a unidade experimental uma bandeja e considerando-se a análise de 20 plantas por bandeja. Para o estudo a campo, o delineamento experimental foi inteiramente casualizado sendo três tratamentos e cinco repetições, com três plantas por repetição.

A semeadura de alface 'Vera' foi realizada no dia 04/05/01, sendo colocada uma semente no centro de cada célula da bandeja, na profundidade de $5 \mathrm{~mm}$. Estas bandejas permaneceram em viveiro de mudas até os 26 dias após a semeadura, sendo realizada a irrigação diária. Após este período, mediu-se o comprimento da raiz $(\mathrm{cm})$ e quantificou-se o número de folhas. Para a obtenção do comprimento da raiz e número de folhas, as mudas foram retiradas das bandejas, levadas ao laboratório e lavadas em água corrente para a retirada do substrato aderente. $\mathrm{O}$ comprimento foi obtido com o auxílio de uma régua graduada em milímetros. Neste dia as mudas foram transplantadas para o canteiro definitivo, com o espaçamento de 50 $\mathrm{cm}$ entre linhas e $30 \mathrm{~cm}$ entre plantas.

Aos 30 dias após o transplantio (28/ $06 / 01$ ) foi realizada a avaliação do desenvolvimento da produção a campo medindo-se o comprimento de raiz $(\mathrm{cm})$ e os pesos de matéria fresca $(\mathrm{g})$ e seca (g) da parte aérea da planta adulta.

Para a avaliação das plantas adultas, estas foram levadas ao laboratório e lavadas em água corrente para a retirada do substrato aderente. O comprimento da raiz foi medido por uma régua graduada em milímetros. Em seguida as plantas foram pesadas em balança digital para obtenção do peso fresco e em seguida colocadas em sacos de papel etiquetados para a secagem em estufa com circulação forçada de ar, a $65^{\circ} \mathrm{C}$. Quando o peso constante foi atingido efetuou-se a pesagem, em balança eletrônica digital.

Os dados obtidos foram submetidos à análise de variância e as médias comparadas pelo teste de Tukey ao nível de $5 \%$ de probabilidade.

\section{RESULTADOS E DISCUSSÃO}

As maiores médias sempre ocorreram nas mudas provenientes de bandejas com maior volume celular (T1). As médias das variáveis comprimento de raiz e número de folhas das mudas produzidas no tratamento T1 foram superiores às dos tratamentos T2 e T3 (Tabela 1). Estes resultados corroboram os obtidos por Oliveira et al. (1993), os quais observaram que o melhor desenvolvimento em mudas de maracujazeiro ocorreu quando foram utilizadas bandejas com menor número de células, independente do substrato utilizado. Possivelmente, por haver um maior volume de substrato envolvendo o sistema radicular, torna-se mais fácil o suprimento de fatores ótimos de produção para o crescimento e o desenvolvimento das mudas (Silva et al., 2000a; Menezes Júnior et al., 2000). O comprimento da raiz e o número de folhas foram maiores no tratamento T2 quando comparado com o tratamento T3. 
Tabela 2. Médias obtidas para comprimento de raiz $(\mathrm{cm})$, pesos da matéria fresca $(\mathrm{g})$ e seca $(\mathrm{g})$ das plantas de alface adultas oriundas das mudas produzidas nos diferentes tipos de bandeja, 30 dias após o transplantio. Presidente Prudente, UNOESTE, 2001.

\begin{tabular}{lccc}
\hline \multicolumn{1}{c}{ Tratamentos } & $\begin{array}{c}\text { Médias do comprimento } \\
\text { de raiz } \mathbf{( c m})\end{array}$ & $\begin{array}{c}\text { Médias do peso da } \\
\text { matéria fresca } \mathbf{( g )}\end{array}$ & $\begin{array}{c}\text { Médias do peso da } \\
\text { matéria seca } \mathbf{( g )}\end{array}$ \\
\hline T1 - 128 células & $14,50 \mathrm{a}$ & $124,4 \mathrm{a}$ & $14,03 \mathrm{ab}$ \\
T2 - 200 células & $14,30 \mathrm{a}$ & $146,4 \mathrm{a}$ & $16,80 \mathrm{a}$ \\
T3 - 288 células & $13,80 \mathrm{~b}$ & $80,5 \mathrm{~b}$ & $9,00 \mathrm{~b}$ \\
\hline CV $(\%)$ & 3,51 & 19,59 & 26,10 \\
\hline
\end{tabular}

*Médias seguidas por letras distintas na coluna, diferem entre si pelo teste de Tukey a 5\%.

Quanto à condução no campo (Tabela 2), houve relação entre o tipo de bandeja utilizada e a qualidade das mudas. Porém, neste caso, os tratamentos T1 e T2 não apresentaram diferenças estatísticas entre si quanto ao comprimento de raiz e pesos fresco e seco da planta. Já o tratamento T3 apresentou as menores médias, implicando em que mudas com pouco desenvolvimento radicular proporcionam piores plantas adultas. Torna-se claro mais uma vez que um menor volume de terra exerce grande influência no comportamento das plantas, afetandolhes a arquitetura, o desenvolvimento, $\mathrm{o}$ peso, a qualidade e, conseqüentemente, a produção (Janick, 1986).

Concluiu-se que as melhores mudas foram produzidas na bandeja com células de maior volume (T1) para todas as variáveis medidas. As mudas do tratamento $\mathrm{T} 2$, embora tenham apresentado menores valores de comprimento de raiz e número de folhas, obtiveram uma recuperação no campo e se igualaram estatisticamente ao desempenho no campo das mudas do tratamento T1. Já o tratamento T3, com menor volume de substrato, produziu as piores mudas e as piores plantas no campo.

Estes resultados concordam com aqueles verificados em testes com bandejas de isopor em outras culturas tais como maracujá (Oliveira et al., 1993), cebola (Cardoso \& Costa, 1999), e quiabo (Modolo \& Tessarioli Neto, 1999) onde as melhores mudas foram obtidas nas células com maior volume.

Desta forma, para a produção de mudas de alface recomenda-se o uso da bandeja de isopor de 200 células, a qual possibilita a obtenção das melhores plantas adultas, com as vantagens da utilização de um menor espaço físico na estufa e da economia de substrato quando comparada à bandeja de 128 células.

\section{LITERATURA CITADA}

ANDRADE JÚNIOR, A.S.; DUARTE, R.L.R.; RIBEIRO, V.Q. Resposta de cultivares de alface a diferentes níveis de irrigação. Horticultura Brasileira, v. 10, n. 2, p. 95-97, 1992.

CARDOSO, A.I.I.; COSTA, C.P. Produção de bulbinhos de cebola em bandejas de isopor. Scientia Agricola, v. 56, n. 4, p. 969-974, 1999.

CARMELLO, Q.A.C. Nutrição e adubação de mudas hortícolas. In: MINAMI, K. Produção de mudas de alta qualidade. São Paulo: T.A. Queiroz, 1995. p. 27-37.

CARNEIRO, J.G.A. Variações na metodologia de produções de mudas florestais afetam os parâmetros morfo-fisiológicos que indicam a sua qualidade. Série Técnica FUPEP, v. 12, p. 1-40, 1983.

DEMATTE, J.B.I.; CASTELLANE, P.D.; SOUZA, A.C.; VOLPE, C.A.; PERECIN, D. Efeitos da fertilização e de quatro substratos na produção de mudas de alface. Horticultura Brasileira, Brasília, v. 13, n. 1, p. 79, 1995.

FILGUEIRA, F.A.R. Novo Manual de Olericultura. Viçosa: UFV, 2000. 402 p.

GODOY, F.; BRAZ, L.T.; CASTELLAN, P.D.; FERREIRA, M.A.J.F. Efeitos de diferentes substratos na formação de mudas de alface. Horticultura Brasileira, Brasília, v. 13, n. 1, p. 85, 1995.

JANICK, J.V. A Ciência da Horticultura. São Paulo: Freitas Bastos, 1986. 486 p.

LATIMER, J.G. Container size and shape influence growth and landscape performance of marigold seedling. HortScience, v. 26, n. 2, p. 124126, 1991.

LUZ, J.M.Q.; COMAR, E.M.; BARBOSA, F.G.; RIBEIRO, L.S.; MENDONÇA, F.C.; GUIMARÃES, T.G. Produção de mudas de alface, de tomateiro e de couve-flor com diferentes lâminas d'água e concentrações de um condicionador de solo. Horticultura Brasileira, Brasília, v. 18, p. 615-617, 2000.

MENEZES JUNIOR, F.O.G.; FERNANDES, H.S. Efeitos de substratos formulados com esterco de curral e substratos comerciais na produção de mudas de alface. Revista Cientifica Rural, v. 4, n. 2, p. 15-23, 1999.

MENEZES JÚNIOR, F.O.G.; FERNANDES, H.S.; MAUCH, C.R.; SILVA, J.B. Caracterização de diferentes substratos e seu desempenho na produção de mudas de alface em ambiente protegido. Horticultura Brasileira, Brasília, v. 18, n. 3, p. $164-170,2000$.
MINAMI, K. Produção de mudas de alta qualidade em horticultura. São Paulo: T.A. Queiroz, 1995. $135 \mathrm{p}$

MODOLO, V.A.; TESSARIOLI NETO, J. Desenvolvimento de mudas de quiabeiro [Abelmoschus esculentus (L). Moench] em diferentes tipos de bandeja e substrato. Scientia Agricola, v. 56, n. 2, p. 377-381, 1999.

NICOULAUD, B.A.L.; MEURER, E.J.; ANGHINONI, I. Rendimento e absorção de nutrientes por alface em função de calagem e adubação mineral e orgânica em solo "areia quartzosa hidromórfica". Horticultura Brasileira, v. 8, n. 2, p. 6-9, 1990.

OLIVEIRA, R.P., SCIVITTARO, W.B.; VASCONCELLOS, L.A.B.C. Avaliação de mudas de maracujazeiro em função do substrato e do tipo de bandeja. Scientia Agricola, v. 50, n. 2, p. 261-266, 1993.

RODA JUNIOR, R.; LUZ, J.M.Q.; SEVERINO, G.M.; SILVA, F.C.; MARCUZZO, K.V. Produção de mudas de alface sob diferentes lâminas d' água e doses do condicionador de solo AQUASORBâ. Horticultura Brasileira, Brasília, v. 20, n. 2, 2002. Suplemento 2. Trabalho apresentado no $42^{\circ} \mathrm{Con}$ gresso Brasileiro de Olericultura, 2002.

SANCHO, J.F.A. The present status of the substrate as an ecosystem component and its function and importance in crop productivity. Acta Horticulturae, v. 221, p. 53-74, 1988.

SILVA, A.C.R.; FERNANDES, H.S.; MARTINS, S.R.; SILVA, J.B.; SCHIEDECK, G.; ARMAS, E. Produção de mudas de alface com vermicompostos em diferentes tipos de bandeja. Horticultura Brasileira, Brasília, v. 18, p. 512-513, 2000a.

SILVA, V.F.; BEZERRA NETO, F.; NEGREIROS, M.Z.; PEDROSA, J.F. Comportamento de cultivares de alface em diferentes espaçamentos sob temperatura e luminosidade elevadas. Horticultura Brasileira, Brasília, v. 18, n. 3, p. 183-187, 2000b.

SILVA JÚNIOR, A.A.; MACEDO, S.G.; SLUKER, H. Utilização de esterco de peru na produção de mudas de tomateiro. Florianópolis: EPAGRI, 1995. 28 p. (Boletim Técnico, 73).

SOUZA, C.G.; RISSO, I.A.M.; CARMO, M.G.F.; SOUZA, J.P.; FERNANDES, M.C.A. Comportamento da produção de mudas de alface em casa de vegetação aos efeitos de biofertilizante líquido. Horticultura Brasileira, Brasília, v. 20, n. 2, 2002. Suplemento 2. Trabalho apresentado no $42^{\circ}$ Congresso Brasileiro de Olericultura, 2002.

VERDIAL, M.F.; IWATA, A.Y.; LIMA, M.; TESSARIOLI NETO, J. Efeito do condicionamento no desenvolvimento de mudas de alface (Lactuca sativa). Horticultura Brasileira, v. 14, n. 1, p. 126, 1996. 